Svitlana Melnychenko, Doctor of Economics, Professor, Kyiv National University of Trade and Economics,

Kyiv Ukraine,

ORCID: 0000-0002-5162-6324;

ResearcherID: N-9535-2016

Mariia Kulyk,

Ph.D. (Economics), Associate Professor, Kyiv National University of Trade and Economics,

Kyiv Ukraine, ORCID: 0000-0001-8732-7441;

ResearcherID: N-3088-2016

Oksana Poltavska,

Ph.D. (Economics), Associate Professor, Kyiv National University of Trade and Economics, Kyiv Ukraine, ORCID: 0000-0002-5285-4302

ResearcherID: N-3064-2016

\title{
DIRECTIONS FOR IMPLEMENTING HOTEL REVENUE MANAGEMENT SYSTEM
}

The article discusses the theoretical and scientific basis of revenue management system in hotel industry, the essence of Revenue management, its functions, process and importance for implementing hotel revenue management system. Applying revenue management in service sector is presented. The authors presented the propositions for implementing Revenue management system in the hotel and developing pricing and non-pricing instruments of hotel revenue management. In the article modern trends and innovations, as well as their features, which are developing in revenue management, technological progress in hotel business are observed

Keywords: revenue management, hotel, hotel business, hospitality, revenue, technology.

\section{Relevance of research topic.}

Revenue management has many different scientific definitions; however, the most accurate will be to say that it is about «selling every product to the right customer at the right time». Even though Revenue management idea was implemented in 1960-s for the first time, many industries still use it and successfully implement it in 
their businesses. Not so many years ago the Revenue management was mostly common only in big hotel chains, but nowadays we can witness how fast this tendency spreads among smaller hotels. Its main feature is that hotels started to implement more personalized policy of price formation towards the customers considering many various factors. Modern entrepreneurs have to note that all the customers have different income and can afford different expenses, and may also have different needs. So using the mechanism of Revenue management the price for the room or service can vary depending on time of the day, particular day's demand (either it is high or low), longevity of stay, requested level of comfort and many other features as well. It is possible to assume, that Revenue management nowadays has a role of a trigger for the sales departments in many hotels and hotel chains.

\section{Formulation of the problem.}

Overall, Revenue management is all about challenging the resources in the importance of gathering information about the market so that the hotel's management can be proactive and not reactive. This all information must be used to divide the market and adjust the product or service through distribution, to the right customer at the right time and at the right price. As Revenue management in the hospitality industry grows, hospitality managers need to be aware of its key role in hotel sales strategy, paying special attention to new market trends. One of the most important benefits of implementing Revenue management is that it provides companies with a better and clearer understanding of what is expected by the customers from the product or service. Many researchers have proved that Revenue management gives hotels a bright insight into specific needs and wants of the customers and guests, it helps to shape and flex the product in a right way in order to satisfy the existing customers as well as to attract new ones. It also allows to «manipulate» the pricing of hotel to make sure it is «right» for the «right» customer.

Revenue management can allow the manager to add or remove some products or services that potentially can benefit. This does not necessarily require big amount of money or resources. In smaller hotels revenue manager can directly contact the guests and ask about their preferences, needs or wants, something that that would like to see in the future or something that they find useless. In order to be a successful hotel it is vital to be in good communication relationship with the guests, especially with returning guests, who can directly advise on the future developments.

\section{Analysis of recent researches and publications.}

There are key levers that help Revenue managers continue the Revenue management strategy of a hotel. Within 30 years these levers have significantly evolved and developed and now they serve a big role for the mangers. Ivanov and Zhechev claim that Revenue management tools can be divided into two categories: pricing and non-pricing revenue management tools. The researchers did not pay much of attention to the price as a variable in Revenue management before 1995. Price was mostly considered as some variable that was provided by a certain third party and that 
was the reason so few companies considered that the price can drive demand and that the prices the hotel offers may not be optimal for someone. Considering the fact that any decision in Revenue management is a result of both a price and duration, it is very important that modern RM models include information that concerns the price and demand, and considers the potential effect of their relation on the revenue maximization.

Dr. Ravi Mehrotaand Mr. James Ruttley offer the conceptual approach to Revenue management that consists of four stages: forecast, optimize, control and monitor. Accurate demand forecasting can be a key to the success of Revenue management in a hotel. The decisions regarding the price policy is more measured and deliberated when there is a possibility to forecast correctly the hotel occupancy and segments of the customers. Once the forecast is prepared, it is easy to foresee the days with the lowest demand. This means that after creating the forecast, there will be a need in decision making processes which can also be called optimization: the booking request should be accepted or denied in order to maximize both the revenue and the hotel occupancy. This step is very significant and it involves taking into consideration all the existing aspects about current hotel's situation.

The stage «control» means to have control over length control (minimal length of stay, minimal stay through and maximal length of stay) in a particular hotel and also rates control. The stage «monitor» is the stage of the process when we compare current situation to the previously expected situation based on the forecasts were made. If the forecast was not correct, this means that the methods of forecast that were used are not effective. In this concept there is no information about human resources. But the author's initial concept was that Revenue management has human resources in the center of the attention and studies, however it cannot be done without modern software and a professional revenue manager. Also, Tranter, Hill and Parker have introduced a different view on the process and key elements of Revenue management

\section{Presenting main material.}

In order to improve its hotel Revenue management needs to, first of all, know its potential market. The hotel's management also needs to learn the competitors in order to be more profitable and competition-resistible. The competitor may not always be a particular hotel in the same location, it can also be various seasons or weekend. The hotel can start using standard metrics of: brand strength, house count, facilities, star rating, etc. Knowing competitor can be useful, because in this way the hotel can investigate and create its own unique service or product that will make it different among other hotels, or also to make sure the hotel is not offering something out-of-date which is commonly used.

The strategy «Think \& book like a customer» is very widely used nowadays as more and more hotels tend to use it while creating or developing a web-page or booking tools. It is very up-to-date matter for hotel, as now they do not have an open price list on their website. In order to make a reservation the potential guest needs to 
fill out the form and wait for the answer. But at the same time it would be a lot more convenient to make a reservation or see the price directly on the spot. The hotel can have strong and rational pricing, but if the customers cannot find it, cannot book it or understand what is offered and make a comparison, and then the hotel is less likely to convert potential customers.

There are plenty of different tools that can provide the management with booking rate but they do not always give the customer's perspective. However, understanding how hotel's Revenue management strategy is «seen» and «bought» from the outside-in is critical [18]. In order to keep the track of regular or loyal customers, to monitor and increase brand awareness and to attract new customers and as a result achieve better revenue and occupancy metrics the following plan is proposed.

\section{Program of implementation of Revenue management}

\begin{tabular}{|c|c|c|}
\hline Task & Responsible person & Frequency \\
\hline $\begin{array}{l}\text { Monitor overall position of the hotel in } \\
\text { a random web search by location and } \\
\text { dates }\end{array}$ & FO agent & Once a week \\
\hline $\begin{array}{l}\text { Search on } 2 \text { or } 3 \text { major OTAs and } \\
\text { check - how are you ranked, compare } \\
\text { in pricing with other hotels (metrics } \\
\text { F\&B, Packages, etc.) }\end{array}$ & $\begin{array}{c}\text { FO agent / } \\
\text { Marketing team } \\
\text { representative }\end{array}$ & Once a month \\
\hline $\begin{array}{l}\text { Make a booking on different cites, } \\
\text { check how competitor assess their } \\
\text { websites, compare how easy it is to } \\
\text { book a room on your website and on } \\
\text { the others }\end{array}$ & FO agent & Once a month \\
\hline $\begin{array}{l}\text { Activate social media presence (e.g. } \\
\text { Facebook page, Instagram): post } \\
\text { pictures, monitor subscribers, likes } \\
\text { and attendance to the page }\end{array}$ & FO agent & Every two days \\
\hline $\begin{array}{l}\text { Create/update a list of loyal } \\
\text { customers, regularly update with } \\
\text { your new services, seasonal offers, } \\
\text { new events, discounts, etc. }\end{array}$ & $\begin{array}{c}\text { FO agent / } \\
\text { Marketing team } \\
\text { representative }\end{array}$ & Two times a month \\
\hline $\begin{array}{l}\text { Develop monthly and weekly pick- } \\
\text { up reports in order to be able to } \\
\text { adjust the prices according to the } \\
\text { current demand and to monitor the } \\
\text { overall condition of the revenue }\end{array}$ & $\begin{array}{c}\text { FO agent / financial } \\
\text { department representative }\end{array}$ & $\begin{array}{l}\text { Every week, report of } \\
\text { total state once a week. }\end{array}$ \\
\hline
\end{tabular}


As we can see from the plan, it does not require any additional expenses for the hotel. All these responsibilities can be completed by the existing staff and they are not very time consuming and do not require special skills. The data received from this research can be followed to the management so that they can apply the needed changes or adjustments. This research will also provide both staff and management with a better understanding how the booking process is for the consumer and what needs to be added or removed. This factor is very important and it can also be one of the reasons of low occupancy and weak revenue.

Knowing one's product and making the most of it is one of the most significant keys to successful Revenue management development. Another key to success is knowing and implementing pricing and non-pricing instruments of Revenue management system. For the hotel it is important to learn either the guests would be willing to book additional services, having an opportunity to book directly at the hotel, not spending hours of searching in the Internet.

Another key point can be adding a lunch menu to the Food and Beverage options in hotel. The hotel can offer special rates for dinner or breakfasts or apply «happy hour» specialty. It is very common, when after implementing these features the organization's revenue starts to grow. This is a real possibility to make the revenue grow, as it can be presented as a «business lunch to go», which allows the staff not to wash the dishes all the time and since it will be open limited time only, the staff can prepare a particular number of the packages ready by the needed time. Average price of a business meal in Kyiv is approximately $100 \mathrm{UAH}$. It also depends on the variety of the dishes that are offered and served, but to start with the hotel can produce 50-70 lunches for an estimated time of the day and to see how profitable it will be. In the future, the number of the requested business lunches can grow.

As the research has shown, little hotels do not have a price differentiation policy. However, implementing one can be rather beneficial. For example, the hotel management knows its high and low seasons, so the prices can vary during these periods. In low seasons, some of the guests can be attracted by the label «sales» or «discount» on a price even if it is only deducted by $10 \%$. Again, as Revenue management principle states, it is better to sell a room for a lowered price, than not selling it and «losing» instead. The hotel management can benefit from implementing discount policy or low rate policy during the season.

Non-pricing instruments of Revenue management, the research has shown that the hotels, even though which have low occupancy, still has some loyal and regular guests. This means the hotel can consider the implementation of some loyalty program. By collecting guests' emails the hotel can «stay in touch» with the guests, alert them about any upcoming discounts or offer some special deals. In such way the hotel shows that it cares about loyal guests and on a psychological level the guests will feel connected to the hotel. Nowadays, discount or loyalty programs are very 
widely used and show successful results of attaching people to the brand and show repetitive use of one's services or purchase of products. Application of this tool can also lead to creation of «lowest price guarantee» tool. The hotel can announce that the first 5 reservations that will be made within one day will have an exclusive «lowest price guarantee» label and in case the customers find any cheaper offer for his hotel, the hotel will return the money. This method is quite effective as well. Social media can play a crucial role for the customer before booking a room in any hotel. Independent reviews encourage the customers a lot more than a simple description of the hotel on its own webpage. Magnuson (2019) stated that once the hotel has information on what the customer thinks of it, then the management can work on that: this can also guide hotel's pricing policies. In general, it is important to know what guests think about the hotel and be aware of social reputation as it is directly connected to the guests' willingness to book. Another non-pricing instrument is distribution channel. As the research has shown, the hotel's attempts of growing internet presence are not very successful. Instead, the duty front office manager, can spend 1 hour per day for posting a new picture, for adding hashtags to it, for monitoring the number of likes and attendance on the official hotel page.

Most of the people use their mobile phones for everything now via the gadget. As we can see, most of the tools require using mobile phone or computer, and Internet so being in trend is one of the keys to successful implementation of Revenue management system. It is vital to follow and monitor the competitors' marketing campaigns and strategies in order to be unique on the market and offer to the guests something that they will not find anywhere else or something that you can be excellent at. The importance of social media and Internet presence are clearly identified for many forms of business activities. High involvement of customers in the hospitality industry is crucial factor of adaption. New ways of communication support the hotels in identifying the customers' needs and wants in order to achieve high guest satisfaction and helps to increase hotels' revenue.

\section{Conclusions}

The results of the research show that Revenue management is a vital and important part of successful functioning of the hotel. Revenue management allows managers to monitor and forecast demand, to optimize the inventory and price availability in order to maximize the hotel's revenue. The main purpose of the Revenue management was identified as selling the room at the right price at the right time to a right customer.

The techniques of Revenue management, their purpose and functions were identified. Price presentation is the step where the hotel announces the price to the customer. Dynamic pricing is one of the latest trends in the hotel industry and it serves for adjusting the prices due to demand. Price discrimination is a selling strategy which aims to receive the maximum possible payment from a particular customer. Lowest 
price guarantee is not only widely used in hospitality industry, but also in many selling strategies of different enterprises. It basically promises the customer to return the difference of the rate found in any outside source. Rate fence is the rule of restrictions that allows the customers to segment themselves based on their needs and willingness to pay.

Other techniques are presented as non-pricing ones. Their purpose is the same: to grow revenue of the hotel. However, they work with some differences than the pricing tools. One of the most important one is room availability guarantee. This service mostly works when a hotel has loyalty program and it can guarantee to its premium guests a room which will be available no matter how big the occupancy at particular period can be. The hotel can also conduct a length of stay control and overbooking. These are very common practices in the hotels and they also help to control and increase the revenue. Capacity management is called and ability to satisfy the demand. One of the most important tools is channel or distribution management. It helps to accelerate the hotels' online presence which is very crucial nowadays due to the mass usage of different gadgets.

\section{REFERENCES}

1. Azadeh, Shadi Sharif, Marcotte, Patrice, and Savard, Gilles. «A taxonomy of demand uncensoring methods in revenue management». In: Journal of Revenue and Pricing Management 13.6 (2014), pp. 440-456.

2. Cannon H. S. 2493 (95th): Airline Deregulation Act [E-source] / Howard Cannon // GovTrack. - 2018. - Access through: https://www.govtrack.us/ congress/bills/95/s2493.

3. Cheung, Wang Chi and Simchi-Levi, David. «Efficiency and performance guarantees for choice-based network revenue management problems with flexible products». In: (2016).

4. Guo, Peng, Xiao, Baichun, and $\mathrm{Li}$, Jun. «Unconstraining methods in revenue management systems: Research overview and prospects». In: Advances in Operations Research (2012).

5. Ivanov, S. and Zhechev, V. (2012). Hotel revenue management - a critical literature review. Tourism Review.

6. Landman, Patrick. The Top 5 Hotel Revenue Management Trends in $2018-$ By Patrick Landman - Hospitality Net. 2019. url: https:// www.hospitalitynet.org/ opinion/4085214.html.

7. Lee, A. O. «Airline reservations forecasting probabilistic and statistical models of the booking process». Massachusetts Institute of Technology, 1990. 
8. Lemke, Christiane, Riedel, Silvia, and Gabrys, Bogdan. «Evolving forecast combination structures for airline revenue management». In: Journal of Revenue and Pricing Management 12.3 (2013), pp. 221-234.

9. Leposa, A. (2014). Revenue management - pricing out social. HotelManagement.net, March p.52

10. Mahmoud A. (2015). Understanding the Role of the Hotel Revenue Manager. Hotel Online.

11. Pan, Bing and Yang, Yang. «Forecasting destination weekly hotel occupancy with big data». In: Journal of Travel Research 56.7 (2017), pp. 957-970.

12. Valadkhani, Abbas and O'Mahony, Barry. «Identifying structural changes and regime switching in growing and declining inbound tourism markets in Australia». In: Current Issues in Tourism 21.3 (2018), pp. 277- 300.

13. Weatherford, L. R. and Belobaba, P.P. «Revenue impacts of fare input and demand forecast accuracy in airline yield management». In: Journal of the Operational Research Society 53.8 (2002), pp. 811-821.

14. Why RM is the new profit management. 2019. url: https://www. eyefortravel.com/revenue- and- data- management/why- rm- newprofit- management.

15. Wu, Doris Chenguang, Song, Haiyan, and Shen, Shujie. «New developments in tourism and hotel demand modelling and forecasting». In: International Journal of Contemporary Hospitality Management 29.1 (2017), pp. 507-529. 